\title{
Examples of complex measures to improve water exchange in marina
}

\author{
Yuriy Dreizis ${ }^{1 *}$ \\ ${ }^{1}$ Sochi State University, 26-A Sovietskaya str., Sochi, 354000, Russia
}

\begin{abstract}
The modeling of the marina and coastal structures near the Anapa city on Black sea coast of Russia have been carried out. The optimal configuration of the protected breakwaters and other hydrotechnical structures are chosen for protecting of the marina area in the Anapa region. This configuration protect the marina from incoming waves impact and guarantee the need water exchange. A flow, induced by breaking wave, is considered as a main factor of the water exchange. Represented results of researches and the variant of engineering decision in sea coastal zone is possible to consider as attempt of management by coastal processes on rather complex sites of the coast with the joint decision about engineering requirements of an object, management of the water quality in the coastal zone of the sea and choice of optimum variants with the least of influence on an environment.
\end{abstract}

\section{Introduction}

For many years an engineering solving on the sea coast were connected only with the maintenance of problems of the immediate protection of separate sites of the coast or creation of local beaches for particular purposes of the recreation. Frequently coastal protective construction violate a natural seawater exchange, and owing to that is occurred the deterioration of the seawater quality. The reason is the absence of a full estimation of influence of engineering decision in hydrotechnical construction on the environment. The attempt to reduce the influence of engineering decision in environment was undertaken during fulfillment of complex researches in Black sea region of Russia (fig. 1).

Anapa on the Russian Black seacoast is the perfect place for rest and children's resort. There were problems connected with a sanitary condition of beaches and with quality of seawater in connection with further development of the region as a recreation area, with construction of new hotels, with the harbor of yacht club and with reconstruction of the port of Anapa. The solution of problems was connected not only with the development of the appropriate engineering offers within the frameworks of recommended coastal protective action, but also with the necessity of the estimation of influence of these offers on the environment.

* Corresponding author: Yurid2006@yandex.ru 
Engineering decisions offered for separate sites of the coast, which different from each other, should be interconnected into a uniform complex of coastal protective actions.

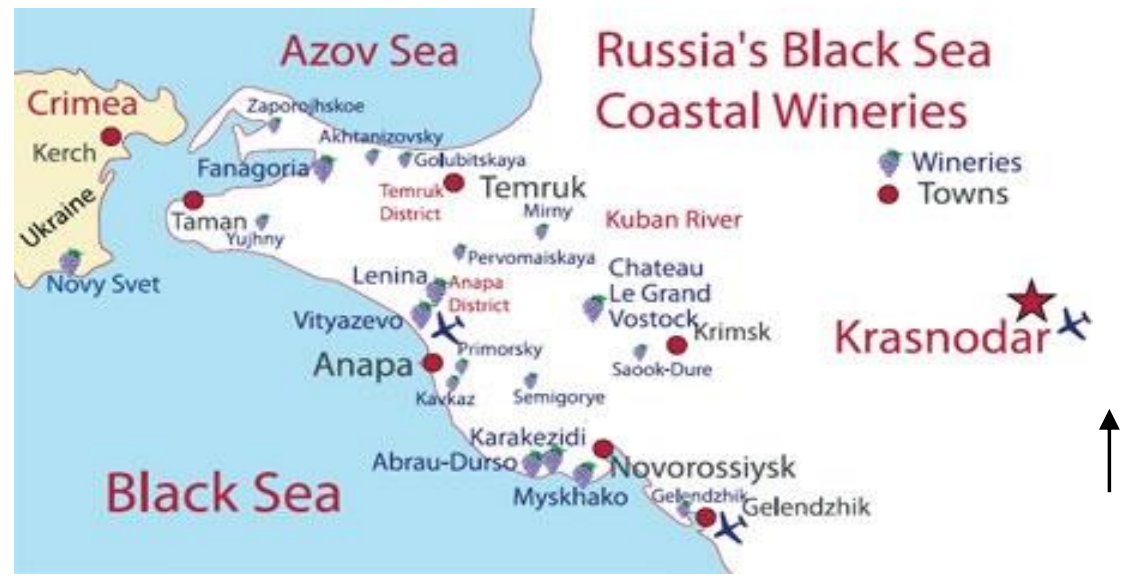

Fig. 1. The schema of studied sites

The coastal zone in Anapa can be divided into three sites, which are characterized by various morphological, recreate and design parameters (Fig. 2).

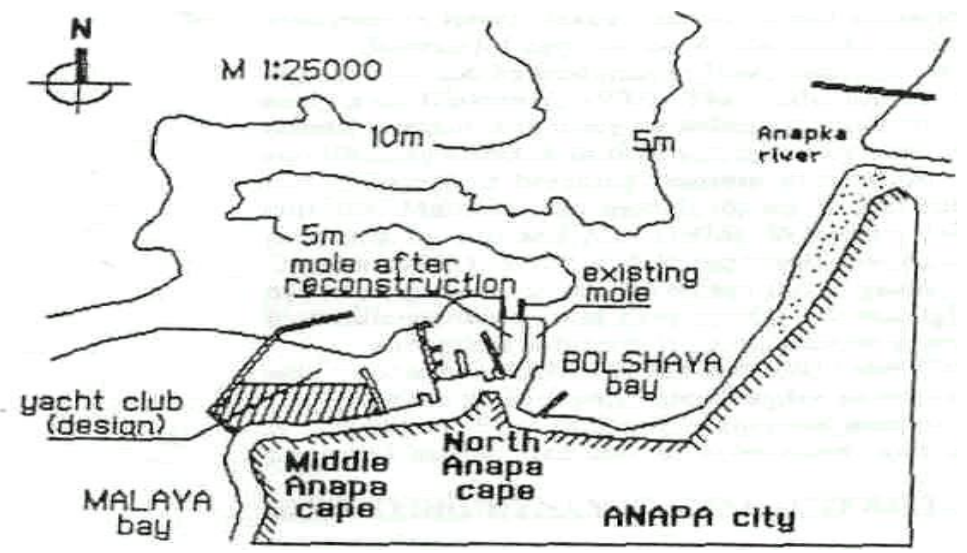

Fig. 2. Study Site Existing and Proposed Structures

The study coastal area is bounded by the Malaya bay and Middle Anapa cape from the west and by North Anapa cape from the northeast. Design of coastal structures including reconstruction of the existing marina, maritime school, yacht club, and shore protective constructions on Anapa coast is the subject of the present study.

The first of them locate between the Southern Anapa cape and the Middle Anapa cape. He extend on $500 \mathrm{~m}$ and includes the Malaya bay, which use for recreate purposes (fig. 3). There are spa-hotels on this site and is being carried out the construction of new hotels on the coast of the bay. There is the shingle beach (the diameter of particles $4-5 \mathrm{~cm}$ ) with the width up to 40 in center and up to $10 \mathrm{~m}$ in the region of capes. The beach existing in a bay is exposed to intensive wave influence. This influence leads to transfer of the beach material towards the Average Anapa cape. Expansion of the beach to $60 \mathrm{~m}$ in the center and to 25 $\mathrm{m}$ in the field of capes with his stabilization in a bay according to the existing sanitary standard is necessary. 


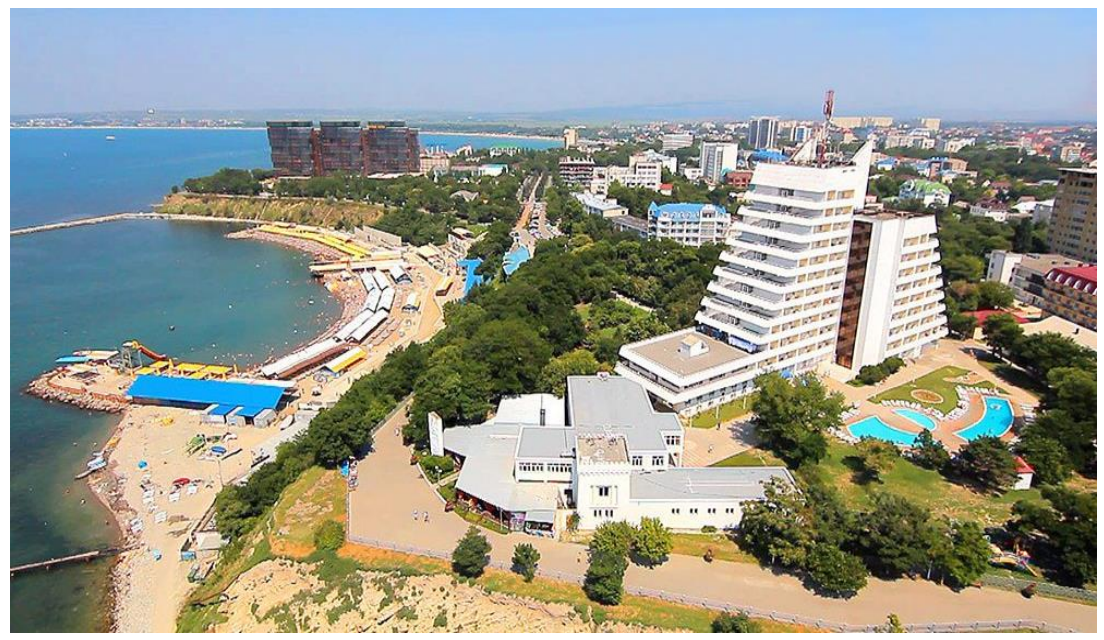

Fig. 3. The Malaya bay

The second part of the coast is $600 \mathrm{~m}$ between the Middle cape of Anapa and the Northern Cape of Anapa and is used in the technical purposes. There are buildings of the 1-st stage of construction of yacht club of Anapa, sea school and port, and here construction of the new yacht harbor is planned. Two piers with a length of 90 and $95 \mathrm{~m}$ and protection of pier for yachts with a length of $60 \mathrm{~m}$ are located in this region. The designed harbor for yachts will be protected by technical structures. The configuration of the protected structures of pier for yachts has to provide protection of the harbor against waves (admissible height of waves in the harbor of 0,2-0,4 m). It demands bigger closing of the harbor. Exchange of water in the harbor by coastal wave currents requires her bigger opening. The existing pier for yachts will be increased the area and will have the sizes of $140 \mathrm{~m}$ of length, $50 \mathrm{~m}$ of width and $1,8 \mathrm{~m}$ of height from water level (fig. 2). Besides, the pier $145 \mathrm{~m}$ long will be constructed. The water territory of marina will be 22500 square meters after reconstruction (fig. 4).

The mathematical and physical modelling of the marina is applied to define the optimal configuration of the marina groine and the method of the washing of the harbor.

The essential influence to this site as in the plan of a wave conditions, and water quality in the coastal zone renders located on the Northern Anapa cape the groine of port in length $230 \mathrm{~m}$, width $50 \mathrm{~m}$ and height over the sea level 1,8 m. Expansion of this groine up to $90 \mathrm{~m}$ is planned at his reconstruction. The groine of the port also renders essential influence on 3rd site of researched Anapa coast, including the Bolshaya bay. This part of the coast used for purpose of recreation. The beginning of the construction of the embankment from the port groine to center of the coastal line of the this bay has resulted in the intensive scour of the sand beach (average diameter of sand is $0,2 \mathrm{~mm}$ ), deterioration of watcher quality in the bay due to formation of stagnation zones near the coastal root part of port groine. Pollution, which moved by longshore current, is accumulated in this part of the bay. The necessity in coastal protective measures, which will be directed on the stabilization of the sand beach in the southern part of the bay, on the improvement of water quality and on the liquidation of stagnation zones near the groine of the port, is very important at this site (fig. 4). 


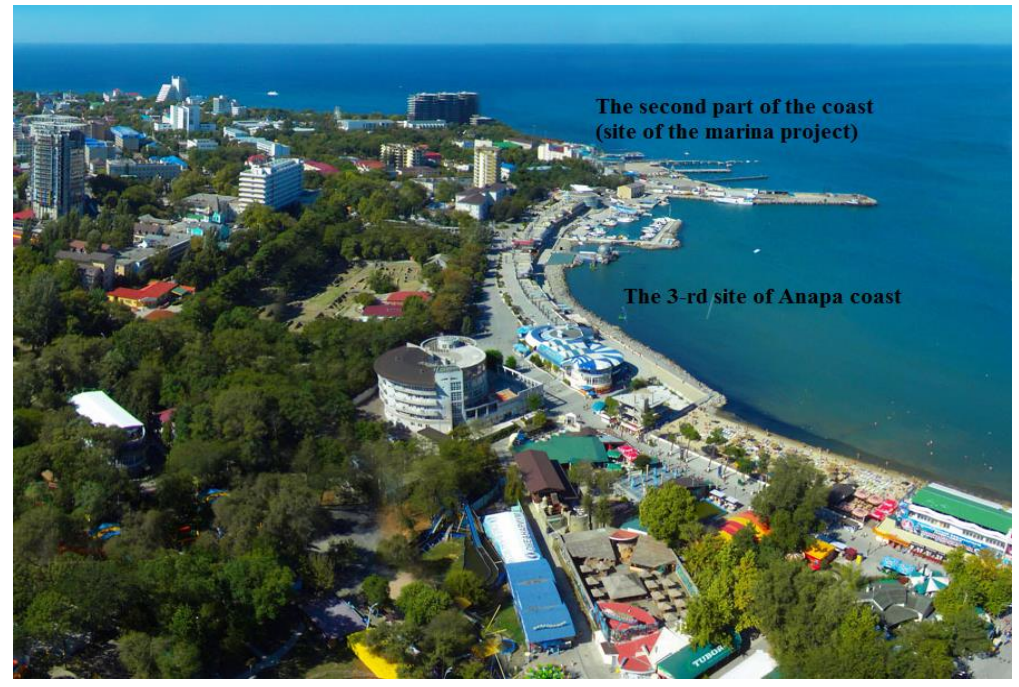

Fig. 4. The second and part

\section{Site hydrodynamic characteristics}

Wave data. The deep-water wave parameters (Hm is the mean wave height and $\mathrm{Lm}$, is the mean nave length) of 5 prevailing wind directions are shown in Table 1. These parameters were obtained by the standard analysis of the hydro meteorological data.

Table 1. Site Wave Data

\begin{tabular}{|c|c|c|c|c|}
\hline Exceedance & \multicolumn{2}{|c|}{ 1 time in year } & \multicolumn{2}{c|}{1 time in 50 years } \\
\hline Direction & $\mathrm{H}_{\mathrm{m}}, \mathrm{m}$ & $\mathrm{L}_{\mathrm{m}}, \mathrm{m}$ & $\mathrm{H}_{\mathrm{m}}, \mathrm{m}$ & $\mathrm{L}_{\mathrm{m}}, \mathrm{m}$ \\
\hline $\mathrm{N}-\mathrm{Y}$ & 0,3 & 8,0 & 0,6 & 12,0 \\
\hline $\mathrm{N}$ & 0,5 & 15,5 & 1,0 & 21,5 \\
\hline $\mathrm{N}-\mathrm{W}$ & 0,9 & 32,5 & 1,9 & 44,0 \\
\hline $\mathrm{W}$ & 2,0 & 65,0 & 4,9 & 141,0 \\
\hline $\mathrm{S}-\mathrm{W}$ & 2,6 & 88,0 & 5,6 & 179,5 \\
\hline
\end{tabular}

Sea water level changes. Obtained maximum sea water level changes are about $0,84 \mathrm{~m}$ over the year. The maximum sea water level takes place in the middle of year, in June-July, and the minimum one corresponds to October.

Drift currents. The stable surface drift current is directed to offshore, to North-West with mean velocity about $0,10 \mathrm{~m} / \mathrm{s}$.

\section{Mathematical modelling of shoreline evolution}

Studied objects much differ by morphological characteristics and by the practical applicability.

The decision of problems put forward and the choice of optimum variants of coastal protective measures was carried out on the basis of mathematical and physical modeling of the processes of the wave refraction, of wave-induced coastal flow and transport of coastal sediment, of evolution of the coastal line, change of water quality in the coastal zone, influence of hydro-technical structures on coast dynamics. 
The waves, field of currents, beach evolution and water exchange for the numerical modelling, too, tests the several variants of the configuration of coastal structures.

Wave refraction. The model of the interaction of wave and current computes the wave refraction in the shallow water. As a result, the parameter of waves, which acting to the structures is obtained.

Shoreline evolution. The modelling of the beach evolution in the Malaya bay under the storm action have been carried out to define the optimal length of the root part of the western groine of marina near the Middle Anapa cape. The applied mathematical model is the quasi 1-D model based on the nonlinear equation of the sediment balance

$$
\frac{d y}{d x}=\frac{2 Q \cot \left(2 \alpha_{b}\right)}{d_{b}\left[1+(d y / d x)^{2}\right]} \frac{d^{2} y}{d x^{2}}
$$

where $Q=$ longshore transport rate of sediment in square meters per second; $y(x, t)=$ variable beach distance from the $\mathrm{x}$-axis ( $\mathrm{x}$-axis is a reference axis parallel to the average shoreline); $\mathrm{t}=$ time; $\mathrm{db}=$ breaker water depth, $\alpha \mathrm{b}=$ breaker wave crest angle.

The length of the groine (root part) is varied from 40 meters lo 80 meters in computations. The angle between mole and shoreline is varied, also.

It correlates well with the similar result of the physical modelling. In total, it is obtain the 50 meters for optimal length of the mole, what is enough for the beach protection in the bay Malaya near the Middle Anapa cape. Our experience shows, that the good 1-D model is often sufficient for most practical computation.

Experience shows, that the good 1-D model is often sufficient for most practical computation.

Permeability of the root part of the western groine of marina and wave damping. The permeable western groine of marina may be applied to increase the water exchange in the harbor. Breaking waves generate the water flow into the marina across the permeable groine. The wave flow transmission through the permeable groine also estimate in this case to obtain the wave height in the marina not above the admissible standard $(0,4 \mathrm{~m})$. The mathematical model is based on the shallow-water equations of wave propagation across permeable breakwaters. It is received in mathematical calculations that the optimal area of pores of the permeable groine is 7,4 square meters, if the permissible maximum wave height in the marina is 0,2 meters. And the optimal area of pores of the permeable groine is 14,8 square meters, if the maximum wave height in the marina is $0,4 \mathrm{~m}$. This permeability is reached by special pipes in the body of the groine with diameter $0,32 \mathrm{~m}$. The needed number of pipes equals to 105 and 210 , in accordance with the permissible wave height in the marina $(0,2 \mathrm{~m}$ and $0,4 \mathrm{~m})$. The hydraulic modelling of various options of the groine structure tested results of the mathematical modelling. Pro-wounds in the groine also was investigated as the variant that is alternative to variant of permeability of the groine by means of the system of pipes.

Wave-induced circulation in the Bolshaya bay and Malaya bay and water exchange. The reconstruction of the port mole with his lengthening can hinder the exchange between some parts of the Bolshaya bay and of the open sea area. Also, the construction of the groine, which blocks the beach in the bay Malaya can hinder of water exchange in the bay. Waveinduced longshore current in the bay is a major factor of water exchange. The computation of the wave-induced circulation in the bay is necessary.

The mathematical model is based on the numerical integration of the depth-averaged hydrodynamic equation for irregular waves. The example of the wave induced current computation in the Malaya bay is present in Fig. 5. 


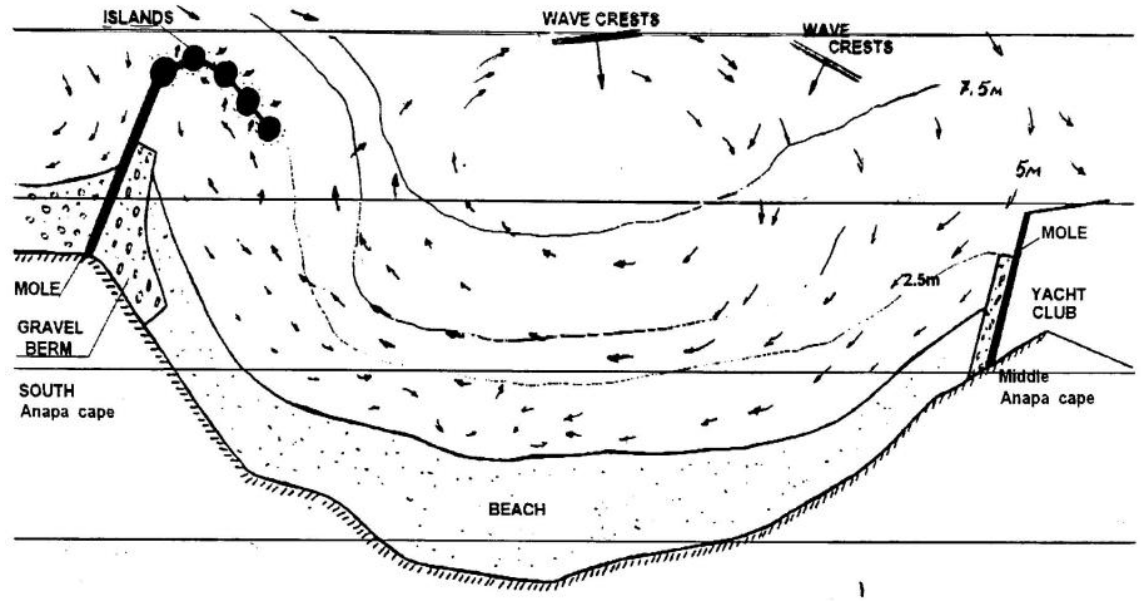

Fig. 5. Proposed structures and the computation example of the wave-induced current field in the bay Malaya

\section{Experimental Faculty}

The experiments of the physical modelling were carried out in basin with the creator of waves. Form of basin is trapezium: bases are 41 and 25 meters and height is 31,5 meters and height of walls is 1,7 meters. Different scales of hydraulic modelling have been chosen for objects of studies. Several physical models, which were defined by problems on sites of the coastal zone, were studied. The scale of modeling of objects of construction in the area of yacht-harbor and in the Malaya bay, of modelling of the shingle beach dynamics and the water exchange was 1:40. Deformed modeling (various vertical and horizontal scales) was used for researching stability of the sand beach in the Bolshaya bay. Vertical scale was 1:20 and horizontal was 1:69 for modeling the site of the coastal zone of the bay Bolshaya.

The wave generator created waves. Extreme waves with exceedance of waves 0,05 were used for modeling of wave loading on hydrotechnical constructions. An average waves with exceedance of the wave 0,50 are applied for modelling of the water exchange. And waves with exceedance of waves 0,30 are applied for modelling of the beach evolution and of the longshore moving of sediments.

The study of each of objects was carried out for several wave-dangerous directions.

Following parameters are measured during researches:

- waves and evolution of the beach in Malaya bay;

- waves in front of protect pierces;

- waves inside marina;

- waves and evolution of the beach in the Bolshaya bay;

- current velocities in the marina and in the Malaya bay;

- influence of various types of hydrotechnical structures on the beach evolution and on the water exchange at the coastal area;

- determination of the optimal configuration and of parameters of objects in the coastal zone.

The several configuration variants of the protective groine for beach in the Malaya bay, configuration variants for protective groine of the yacht-harbor, the configuration of the shoreline in bays Bolshaya and Malaya on the Anapa coast were studied. The wave-induced 
currents and water exchange have been measured near objects of projected constructions. Objects were investigated for several danger directions of waves (Fig. 5).

The studies were conducted for various alternative variants of coastal structures and their layout.

The main attention has been paid to the construction of the yacht-harbor groine and her water exchange.

\section{Results}

The best results of the beach protection, wave damping in marina and water exchange in the harbor area are obtained in case used permeable coastal groine.

Wave damping by the permeable western groine of marina. The constructive design of the studied root part of the western groine of the yacht-harbor is represented in Fig. 6.

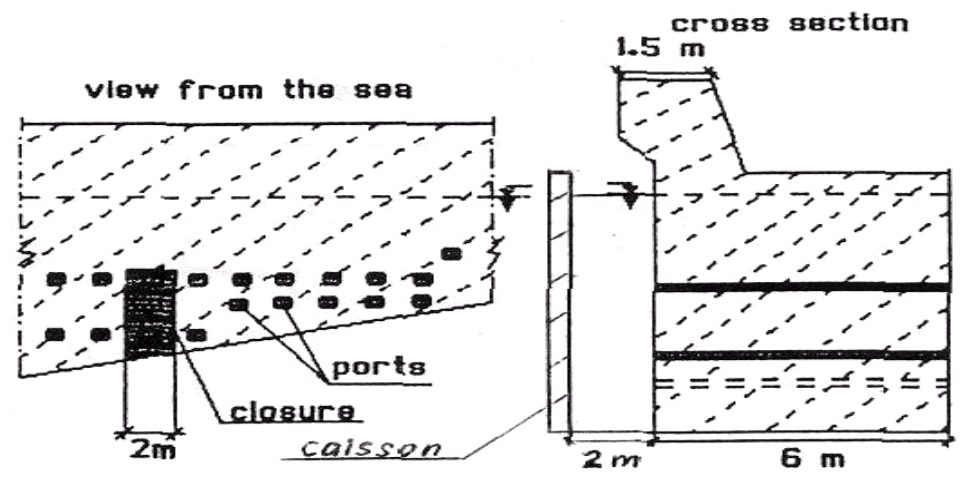

Fig. 6. The schematic diagram of the design of the western groine of yacht-harbor

Best results both for wave damping and for washing of the yacht-harbor are received for a permeable root part of the western groine of the marina.

105 permeable ports with diameter $32 \mathrm{~cm}$ and with total area 7,42 square m, which are placed with the distance $2 \mathrm{~m}$ from each other give the required value of permeability of the groine. Additionally, it are use 7 shutters, which close permeable ports, and have $2 \mathrm{~m}$ of width and the varied height along the groine. Their quantity was computed by the numerical modelling of the wave transmission through the permeable structures before the physical modelling. The using of shutters at the each permeable port gives the possibility to control the direction of the wave flow - only into the internal water area of the yacht-harbor.

Additionally, the construction of the caisson with length $100 \mathrm{~m}$ in the front of the western marina groine from the coast to the sea was researched for the increase of the wave flow into the harbor area (Fig. 5). Use of shutters and caisson created a bigger wave stream, which passed through the permeable groine to the water area of the yacht-harbor in this case. The combine using of the permeable groine and caisson give best conditions for water exchange in the yacht harbor.

The forced pumping of outside seawater to the water area of yacht-harbor was considered as an alternative variant of water exchange in marina. The seawater was pumped to the marina through the system of the permeable pipes, placed in the marina along the perimeter of groine. The propagation of water inflows to the marina is studied by the numerical modelling, also. The comparison of the measured and calculated flow velocities shows the good correlation between mathematical and hydraulic modelling.

The groine permeability showed the sufficient destruction of incoming waves as on the data's of the mathematical modelling, and as on the data's of the physical modelling. In the 
same time, it gives the possibility to create the water flux into yacht-harbor for good water exchange.

The study of several variants of controlling of by the parameter of permeability with using of shutters shows that the optimal variant is the variant with the permeably opening in form of square, which equals area of an opening is 7,4 square meters. The maximum wave height in the marina with this variant is $0,4 \mathrm{~m}$. Such height of waves is the maximum admissible in the yacht harbor.

Water exchange in harbor water area with variants of her natural washing. Water exchange between marina area and the open water is studied on the physical model with using of measuring of the evolution of concentration of $\mathrm{NaCl}$ in several typical points of the protected area.

The additional vertical walls divided area of harbor. Every from this area was salted with the uniform initial concentration 2 gram $\mathrm{NaCl}$ per liter of volume at the start of the each experiment. Experiments began after walls were taken out. The evolution of the salinity concentration $\mathrm{C}(\mathrm{t}) / \mathrm{C} 0$ in yacht-harbor is measured from the initial concentration $\mathrm{C} 0$ to the finite concentration $\mathrm{C}(\mathrm{t})$ during the waves action from various directions.

Markers with zero buoyancy measured wave-induced velocities of current in the same time. The results show that the wave reflection from the groine and creating of circulative zones complicate the water exchange inside marina. However, in spite of that, the measured evolution of the concentration of salinity and velocities of current in the harbor correlate with each other.

The next cases of the natural mixing have been studied:

- impermeable groine;

- permeable groine with several opening square, controlling by shutters at ports and closures;

- groine with caisson. The caisson is $100 \mathrm{~m}$ long and has to be constructed at distance 2 meters from the main groine. His design begins from the coast and proceeds until the end of the groine.

The level of the caisson wall is 0,6 meters above the still water level. If the wave is over-topping, the caisson increases the water inflow to the yacht-harbor through the permeable groine. It works as the natural pump. The best variant of the water exchange in yachtharbor is the using of the permeable root part of the western groine with area of opening 7,4-14,8 square meters. Besides, application of shutters in permeable pipes for their closing at the returned movement of a wave stream and also construction of caisson near the waterpermeable groine gives sufficient increase in water flow into the yacht-harbor and reduction of time of water exchange in 2-5 times. This stream also liquidates stagnant zones on the water area of the harbor.

Water exchange at artificial washing the harbor. The natural washing the water area of the yacht-harbor by the wave-induced flow is worst in the summer period. The number and the power of storms is smaller in this period. Moreover, the summer period is the time of the more active using of the marina. The bigger pollution of the water in the harbor is the result of the active using of the marina.

Possibility of the organization of periodic compulsory washing of the water area of the yacht harbor also it has been investigated. The perforated tubes were placed along the perimeter of the impermeable part of groine and along the embankment, at $1,5 \mathrm{~cm}$ in hydraulic model $(0,6$ meters in the nature) under the water level. The tubes were connected with the pump, which took a water from a deep-water part of the sea.

The water consumption into the yacht-harbor was established by selection of quantity and of the distribution of perforated pipes. The diameter of the opening of perforated tubes was $3 \mathrm{~mm}$ (in hydraulic modelling). The maximum of the water consumption of the pump was 0,162 cubic meters per hour. 
Velocities of the forced current are directed from groine to the center of the yachtharbor in this variant of water flushing. The placing of perforated tubes near walls (groine and embankment) and on the given depth of the water gives the possibility to obtain maximum velocities of current. This variant is analogy of well-known studies of pneumatic breakwaters. The experiments have been carried out without waves and for two consumptions of the pumped water: 0,15 liter per second and 0,30 liter per second (for modelling). Recalculation in field scale gives values 1,5 cubic meters per second and 3,0 cubic meters per second, accordingly. It correlate with wave current across the permeable groine with openings, the total area are 7,4 and 14,8 square meters accordingly.

The time of the complete flushing of the area of the harbor was obtained as 50 minutes in modelling ( 5 hours in the nature) with the first water discharge $(0.15$ liter per second). And the complete flushing time was obtained across 25 minutes $(2,5$ hours $)$, with the double water discharge ( 0.3 liter per second). The forced flushing of the yacht-harbor may be using in combination with the natural waves, and in this case the effect will be increased.

\section{Conclusions}

Chosen options of the new coastal structure gave best results for the beach protection and water exchange in complex and may be used in practice of coast protection.

Based on this study the following conclusions are made:

1. This result of complex researches of problems in the sea coastal zone may be considered as possible attempt of the management of coastal processes on rather large sites of the coastal zone. The complex problem of coastal engineering and ecology problems in combination with economic and recreate problems, with the management of water quality in the sea coastal zone, with the estimation of influence of accepted engineering decisions in the environment has been investigated.

2. The best results of the beach protection, wave damping and water exchange in marina are obtained in case used the permeable coastal structure.

3. The permeable western groine of marina gives the needed wave damping, which is defined by the condition of mooring in the yacht-harbor. The permeability is provided with pipes with diameter 0,32 meters, or big openings near the bottom with size: 2 meters width and 0,5-1,5 meters height. The total area of openings is in the range 7,5-15 square meters.

4. The given permeability of the groine secures the natural washing in the yacht-harbor by wave-induced fluxes into the inside part of marina. The washing may be increased if to apply shutters at the ports of the groine (pipes and openings), which prevent the return of the water flow from the water area of the yacht-harbor, and increase the direct water flux into the marina. The additional effect may be obtained by construction of the caisson in front of the groine with crest level 0,6 meters over the sea water level.

5. In the same time, groine protects the gravel beach in the Malaya bay.

6. The forced flushing of the harbor by the pump across the system of perforated tubes may be recommended in combination with the natural flushing. The last is important, because the natural flushing is not possible without the storm waves.

7. The applied study technique, which includes the mathematical and physical modelling, may be used for designing of the other similar coastal projects.

Represented results of researches of problems of the sea coastal zone dynamics is possible to consider as attempt of management by coastal processes on rather large and complex sites of the coast with the joint solving of problems of construction, management of the water quality in the coastal zone of the sea and choice of optimum variants with the least influence on an environment. 


\section{References}

1. E. Ozhan Proc. 3rd International Conference on Coastal and Port Engineering in Developing Countries (COPEDEC III), 2, 1337-1350 (1991)

2. E. Ozhan and E. Tore. Studies for improving the flushing ability of Marmaris marina. In Planning and Feasibility, (Computational Mechanics and Thomas Telford, London, 1992)

3. I. G. Kantardgi, F. G. Mairanowsky and N. O. Sapova Coastal Engineering, 6 (1995)

4. I. G. Kantardgi, Yu. I. Dreizis Proceeding of the Second International Conference of the Mediterranean Coastal Environment (MEDCOAST 95), 1805-1817 (1995)

5. Guidance on marina sanitation pump outs. Report of working group No.7 / PIANC, (1997)

6. Yu. Dreyzis, E. Bondareva, N. Grishin and I. Proc. of the 7 Int. Conf. «COPEDEC VII», Dubai, UAE. COPEDEC VII, (2008)

7. Yu. I. Dreyzis, E. V. Bondareva, I. G. Kantarzhi, Nauka Kubani, 3, 53-64 (2008)

8. Yu. I. Dreizis, L. V. Prokhoda-Shumskikh Proc. of 9-th International Conference MEDCOAST 2009, 863-874 (2009)

9. Yu. I. Dreizis, E. V. Bondareva and I.G. Kantardgi 9-th International Conference on the Mediterranean Coastal Environment (MEDCOAST IX), 765-776 (2009)

10. Yu. I. Dreyzis, I. G. Kantarzhi and L. V. Vestnik MGSU, 1, 66-73 (2010)

11. S. B. Kuklev, B. V. Divinskiy and Yu. S Kozachinskiy, Gidrotekhnika, 3 (24), 26-30 (2011)

12. Yu. I. Dreizis, E. V. Bondareva, I. G. Kantardgi Proc. of the 8th Int. Conf. on Coastal and Port Engineering in Developing Countries COPEDEC 2012, 20 (2012)

13. I. G. Kantarzhi, V. S. Maderich Magazine of Civil Engineering, 2, 75-80 (2013) 